\title{
REDES DE RELAÇÕES SOCIAIS E ACESSO AO EMPREGO ENTRE OS JOVENS: O DISCURSO DA MERITOCRACIA EM QUESTÃO
}

\author{
Mariléia Maria da Silva*
}

\begin{abstract}
RESUMO: Este trabalho consiste em analisar a trajetória de inserção profissional dos egressos do ensino superior, enfatizando as formas de acesso empregadas pelos jovens para alcançar um emprego, relacionando-as às redes de relações sociais. $\mathrm{O}$ discurso em voga, sobretudo proveniente dos arautos das agências de consultoria de recursos humanos, enfatiza o aumento da qualificação como antídoto contra o desemprego. $\mathrm{O}$ estudo se pauta nos dados obtidos para elaboração de tese de doutorado. Os resultados da pesquisa apontam três modos predominantes de acesso ao emprego: "intermédio da família", "intermédio dos amigos" e "concurso público". Nesse sentido, a garantia de estabilidade no emprego representada pelo ingresso no setor público e as formas particularistas são as que se destacam, o que contraria o discurso da excelência da competitividade como fator determinante na conquista e permanência no emprego.
\end{abstract}

Palavras-chave: Jovens. Graduados. Inserção profissional. Redes sociais. Emprego.

SOCIAL NETWORKS AND ACCESS TO EMPLOYMENT AMONG YOUTHS: QUESTIONING THE MERITOCRACY DISCOURSE

ABSTRACT: This paper analyzes the professional insertion trajectory of graduation and post-graduation students. It traces the ways followed by youths to have access to employment and associates them to social networks. The discourse in vogue, which

Doutora em Educação e professora associada do Departamento de Ciências Humanas da Universidade do Estado de Santa Catarina (UDESC).E-mail: marileiamaria@hotmail.com 
Redes de relações sociais e acesso ao emprego entre os jovens...

mainly comes from human resources consultation agencies, stresses qualification as an antidote against unemployment. This study is based on an analysis of the data obtained to elaborate a PhD thesis, whose results point out three predominant ways to have access to employment: "family", "friends" and "civil service exams". Thus, the guaranty of employment stability represented by the admission in civil services and particularistic ways stand out, which contradicts the discourse on the excellence of competitiveness as a determinant factor to conquer and keep an employment.

Key words: Youths. Graduates. Professional insertion. Social networks. Employment.

\section{Introdução}

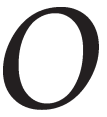

discurso que enfatiza a lógica individual como fonte produtora de riquezas, característica marcante da retórica neoliberal, tornase mais perverso quando examinadas as condiçóes atuais em que estão os trabalhadores e, em particular, os jovens, no que diz respeito às possibilidades concretas da venda de força de trabalho ao capital. Ou seja, a crescente precarização das relaçôes de trabalho, incluindo a ameaça real do desemprego, na contemporaneidade, tem contribuído sobremaneira para a configuração de um contexto em que está em jogo até mesmo a produção da própria existência do trabalhador enquanto mercadoria imprescindível à acumulação capitalista.

Nos últimos anos, sobretudo a partir da década de 1970, muitos estudos têm enfatizado o surgimento de um novo padrão de acumulação capitalista em substituição ao modelo taylorista-fordista, até então predominante (Antunes, 1995, 2000; Ferretti et al., 1994; Frigotto, 1996; Harvey, 1994; Tumolo, 2002). Tal mudança refere-se ao esgotamento desse antigo padrão para atender às necessidades apresentadas pelo capitalismo no seu momento atual, impondo assim novas formas na relação capital-trabalho.

A materialização desse novo modelo de acumulação capitalista, denominado por Harvey (1994) de "acumulação flexível", pressupõe a existência de inovaçôes tecnológicas tanto de base física quanto organizacional. Isso significa que, enquanto o taylorismo/fordismo é fundamentado na produção em massa de mercadorias e pressupõe a atuação de um 
trabalhador fragmentado e parcelizado, esse novo padrão de acumulação organiza-se em processos de trabalho integrados e flexíveis, com o uso intenso de inovações tecnológicas, enxugamento dos postos de trabalho e exigência de um novo trabalhador dito "polivalente" e "multifuncional".

Assim, uma das consequências diretas do capital na busca de racionalização e flexibilização dos processos de trabalho está na manutenção de altos níveis de produtividade, dispensando parte da mercadoria força de trabalho.

Neste artigo, apresento algumas reflexôes a respeito das formas utilizadas pelos jovens, egressos do ensino superior, para conquistar um emprego, situando-as na nova lógica de organização do capital, em que a exigência por mais qualificação - como condição para a efetivação de um contrato de emprego - convive, lado a lado, com um mercado de trabalho progressivamente excludente e debilitado.

A partir do estudo sobre os egressos de três universidades - duas pertencentes ao setor público e uma ao setor privado -, foi possível constatar que a maneira pela qual os jovens têm acesso ao emprego, na atualidade, revela, em certa medida, além do seu pertencimento social, as condiçôes de fragilidade impostas pela nova lógica de acumulação capitalista. Isso evidencia a inconsistência dos discursos que enaltecem as características escolares como exclusivas para a aquisição de um emprego.

$\mathrm{O}$ presente artigo está dividido em duas partes. Na primeira, analiso as principais mudanças nas formas de acesso ao emprego entre os jovens egressos do ensino superior no Brasil, resultantes da deterioração das relações de trabalho, especialmente a partir dos anos de $1990 . \mathrm{Na}$ segunda, identifico alguns estudos franceses que abordam a questão das redes de relações pessoais como meio importante a ser considerado na análise sobre o acesso aos empregos. Tal hipótese foi confirmada a partir de estudo com egressos do ensino superior público e privado em Santa Catarina, no qual as formas particularistas de acesso ao emprego (ajuda da família e de amigos) e o ingresso por concurso público se destacam; contrariando os discursos, ora vigentes, de que o mercado de trabalho, considerado neutro e justo, é capaz de, por si só, reconhecer os mais capazes e garantir-lhes a estabilidade profissional simplesmente pela capacidade de ser competitivo. 
Redes de relações sociais e acesso ao emprego entre os jovens...

As principais vias de acesso aos empregos entre os jovens diplomados no contexto da precarização das relações de trabalho

Segundo Pochmann (1998), os jovens, tradicionalmente, ingressavam no mercado de trabalho de maneira diferenciada, distinção que está relacionada ao segmento social ao qual pertencem. Desse modo, os jovens pobres comumente entravam no mercado de trabalho antes dos 16 anos, sem completar o período escolar obrigatório, e eram admitidos nos segmentos pouco qualificados. Os jovens pertencentes aos segmentos médios normalmente concluíam o período escolar obrigatório ou o ensino profissionalizante, ingressavam antes dos 20 anos de idade nos postos intermediários da grande indústria e dos serviços, bem como no setor público. Os jovens das camadas sociais com maior poder econômico buscavam permanecer mais tempo na inatividade, geralmente cumpriam o ensino superior e entravam no mercado de trabalho após os 20 anos de idade, ocupando postos hierárquicos mais elevados nas principais atividades dos setores público e privado.

Pochmann (2000) apresenta quatro segmentos de mercado que auxiliariam na análise sobre o movimento, tanto dos diferentes padrões de inserção profissional dos jovens quanto da própria heterogeneidade do mercado de trabalho. São eles: segmento profissional, segmento interno, segmento externo e segmento não-organizado.

No segmento não-organizado predominaria a ocupação por jovens que não concluíram o ensino obrigatório. As condiçôes de trabalho são extremamente precárias, como a inexistência de direitos trabalhistas, contratos de trabalho muitas vezes em condiçōes ilegais, pouca interferência do setor público, entre outros. Esse tipo de ocupação é apontado como característico das economias capitalistas periféricas.

O segmento de mercado de trabalho externo se caracterizaria pela concorrência entre trabalhadores de diferentes faixas etárias, sofrendo pouca regulação. A exigência de qualificação geralmente é baixa, a demanda de força de trabalho é formada por empresas de menor porte e elevada instabilidade contratual. Os sindicatos têm dificuldade de penetração, haja vista a dispersão geográfica das unidades produtivas. Existem várias maneiras de uso e remuneração dos trabalhadores, tipos diversos de contratação, e não há estímulo à capacitação profissional nem perspectiva de progressão funcional. Com frequência, o jovem ingressa 
nesse segmento imediatamente após a finalização do ensino obrigatório, ou, até mesmo, antes disso.

O segmento de mercado de trabalho interno corresponderia às grandes empresas, nas quais o ingresso tende a ocorrer por intermédio de critérios definidos pelo próprio empregador ou pelos sindicatos, quando a atuação é mais forte. Há possibilidades concretas de ascensão funcional, por meio de programas de carreira profissional que estimulam a aquisição de formação especializada e o tempo de serviço na empresa. A elevação salarial se estabelece pela passagem por várias posições ocupacionais durante a vida ativa do jovem. É comum ele apresentar escolaridade básica e intermediária, o que pode significar o ingresso no mercado de trabalho, geralmente, depois dos 15 anos. O contrato do jovem, via de regra, justifica-se pela necessidade de renovação de qualificação dos empregados e adequação da estrutura etária dos trabalhadores de uma grande empresa.

No segmento de mercado profissional, a inserção tenderia a ocorrer mais tarde, após a conclusão do curso superior. $\mathrm{O}$ jovem possui maior mobilidade interempresa e intrassetor da atividade econômica. O diploma de conclusão do curso superior é visto como fator indispensável a ser utilizado na trajetória ocupacional de longo prazo. A fase de inatividade do jovem é relativamente longa, já que seu ingresso no mercado de trabalho é após os 20 anos de idade e em postos de trabalho qualificados.

A categorização exposta, conforme apresentada pelo autor, sofreu profundas modificações. As condições de entrada nos diferentes segmentos do mercado de trabalho foram alteradas substancialmente, provocando um processo de deterioração no padrão de inserção profissional dos jovens. Mesmo os mais escolarizados não se encontram numa situação de grandes vantagens, o que pode ser explicado pelo aumento progressivo de jovens portadores de diplomas, combinado com uma política explícita de contenção de gastos adotada pelas grandes empresas, representada não apenas pela dispensa de trabalhadores, mas também pela intensificação da jornada de trabalho e redução salarial. Nesse sentido, pode-se afirmar que "(...) as ocupaçôes que eram portas de entrada dos jovens no primeiro emprego apresentam-se, atualmente, como objeto de disputa entre os jovens e aqueles adultos que possuem maior escolaridade e qualificação" (Salm et al., 1997, apud Pochmann, 1998, p. 57). 
Redes de relações sociais e acesso ao emprego entre os jovens...

Para Pochmann (op. cit.), baseado em pesquisadores franceses (Vernières, 1997; Trottier, 1998), o padrão de inserção ocupacional do jovem $^{1}$ se define pela passagem de situação de inatividade (família e escola) para a situação de atividade (emprego e desemprego) e compreende três componentes básicos: a saída da escola (sistema de ensino), o encontro de um emprego regular (mercado de trabalho) e a constituição de uma família (sociedade). Em determinados momentos históricos, em que as formas de transição da inatividade (família e escola) para a atividade (emprego e desemprego) são menos instáveis e problemáticas, a possibilidade de exclusão social da juventude é menor.

O que se verifica no momento atual é que o processo de dilapidação das condições de trabalho não somente causa a deterioração no padrão de inserção ocupacional dos jovens, mas, sobretudo, altera consideravelmente essas etapas que marcam a passagem da situação de inatividade para a de atividade.

De acordo com Galland (1991), as dificuldades de ingresso no mercado de trabalho têm favorecido certo alongamento dos estudos e também a protelação da constituição de um núcleo familiar. Ou seja, diante do adiamento do ingresso no mercado de trabalho e a consequente dificuldade em conquistar certa autonomia financeira, os jovens tendem a permanecer mais tempo na casa dos pais, resistem à ideia de constituição de uma nova família e retardam a saída da escola, tida como uma alternativa frente ao desemprego.

Permanecer na escola parece significar aos jovens uma estratégia para enfrentar a competitividade no mercado de trabalho, seja por acreditarem que estão se capacitando para o atendimento às demandas do setor produtivo, seja por estarem interessados na aquisição de um diploma que os coloque num patamar diferenciado em relação a uma relevante parcela que não consegue, sequer, obter a escolaridade mínima. Segundo Pochmann (1998, p. 42), "a escola parece se transformar, algumas vezes, em uma espécie de refúgio temporário do jovem diante do quadro de generalizada escassez de emprego, (...) uma estratégia oculta de disputa por uma vaga, uma das marcas do novo padrão instável e competitivo de inserção ocupacional".

Sanchis (1997), ao estudar a População Economicamente Ativa (PEA) na Espanha, defende a ideia de que não é o sistema educativo o responsável pelas dificuldades de inserção dos jovens no mercado de trabalho, mas o próprio funcionamento do sistema produtivo. $\mathrm{O}$ argumento 
utilizado pelos meios de comunicação, em geral, é que a escola não estaria devidamente qualificando para o mercado e que, portanto, esses jovens teriam dificuldades em lidar com tecnologias avançadas, fundamentais para o novo trabalho. $\mathrm{Na}$ verdade, pesquisas demonstram que existe pouca relação entre a taxa geral de desemprego e o nível médio de educação da população. $\mathrm{O}$ autor legitima suas observações citando a seguinte constatação de Errando: "o tipo e o lugar de trabalho dos jovens vem determinado em boa medida pela posição social e ocupacional dos pais"(Errando apud Sanchis, 1997, p. 120).

Para Sanchis (1997), atualmente, o que tem predominado na Espanha, em relação às vias universais de acesso ao emprego, são as formas particularistas, definidas pela posição social e a relação familiar e pessoal do candidato ao emprego. Essa tendência vem sendo fortemente reforçada pela crise econômica. Nesse sentido, quanto melhor é o trabalho em termos de salário, garantias contratuais e estabilidade, maior é a interferência da família.

Concordando com o autor, o mercado de trabalho juvenil somente é homogêneo em sua aparência. Mesmo que em certa medida o acesso ao sistema de ensino tenha favorecido uma relativa "igualdade de condiçôes" entre os jovens de diferentes camadas sociais, permitindo que se encontrem nos mesmos segmentos do mercado de trabalho, existem grandes possibilidades de que a sociedade, por sua própria estrutura de classe, os separe.

Embora estando de acordo com a hipótese de que a continuidade dos estudos tende a expressar um mecanismo de adiamento do confronto com o mercado de trabalho, ressalto que, entre os jovens brasileiros portadores de diploma de graduação, a continuidade dos estudos não elimina a presença no mercado de trabalho, ${ }^{2}$ ou seja, não são situações excludentes.

Dois aspectos devem ser considerados, no que se refere ao fenômeno do "alongamento" dos estudos, como estratégias de enfrentamento das adversidades no ingresso no mercado de trabalho. Em primeiro lugar, é certo que a população escolarizada no Brasil é superior em proporção às décadas anteriores, o que não significa que tenhamos alcançado níveis razoáveis de incorporação demandados pela população em idade escolar. Assim, quando se aponta para um "alongamento da escolaridade" no Brasil, é preciso atinar que estamos falando, em termos estatísticos, de um contingente significativamente pequeno. 
Redes de relações sociais e acesso ao emprego entre os jovens...

Em segundo lugar, tal alongamento, visto como um substituto temporário da inserção no mercado de trabalho - ou seja, os jovens, por falta de oportunidades ocupacionais, acabam investindo nos estudos e estendendo seu tempo de permanência na escola -, exige um cuidado redobrado, uma vez que, mesmo entre os que conseguem alcançar níveis mais altos de escolaridade, é expressiva a quantidade dos que mantêm, concomitantemente aos estudos, algum tipo de inserção no mercado de trabalho, ainda que em situação provisória.

Para muitos jovens, é a própria permanência em alguma atividade que lhes propicia um rendimento financeiro, a garantia de poder dar continuidade aos estudos. Para outros, o trabalho pode estar relacionado menos a um imperativo financeiro e mais aos aspectos ligados à experiência, sociabilidade e outros (Madeira, 1986; Cardoso \& Sampaio, 1994). Tanto em um sentido quanto em outro, o desempenho de alguma atividade remunerada, durante os estudos, coloca-se como uma estratégia de enfrentamento das restrições ocupacionais.

Percebo que a exclusividade aos estudos, como adiamento do confronto com o mercado de trabalho, pode ser realizada por uma parcela reduzida da população universitária, evidentemente pelos jovens pertencentes às famílias com maior recurso financeiro. No entanto, é frequente a presença de muitos destes no mercado de trabalho.

$\mathrm{Na}$ atualidade, diante das altas taxas de desemprego, em especial entre os mais jovens, e da vinculação apelativa nos meios de comunicação de que os jovens apresentam dificuldades na inserção no mercado de trabalho devido à ausência ou insuficiente experiência profissional, é possível supor que essa busca pelo trabalho, ainda no período de graduação, pode significar uma estratégia de enfrentamento das possíveis adversidades no futuro profissional, uma forma de precaução diante da ausência de perspectivas otimistas.

Pode-se concluir que o efeito "antecipador" da ida para o mercado de trabalho, combinado ao efeito "retardador" da saída do sistema de ensino, faz parte de um mesmo processo que tende a caracterizar a inserção profissional dos jovens na atualidade.

As redes de relações pessoais como indicativo da qualidade do emprego entre os jovens

Não são recentes os estudos que abordam a importância das redes de relações pessoais na obtenção e qualidade dos empregos (Silva, 2004, 
2005). Sobretudo entre os franceses, muitos trabalhos têm destacado a necessidade de investigar a situação profissional dos jovens, tendo como ponto de partida suas redes de relações pessoais. Já nos anos de 1970, Granovetter $(2000)^{3}$ ressaltou o significado das redes de relaçóes pessoais na obtenção e qualidade dos empregos.

Pesquisadores franceses (Marry, 1983; Degenne et al., 1991; Epiphane \& Martinelli, 1997) têm se dedicado a discutir as redes de relações sociais como um importante canal a ser investigado para a compreensão das formas pelas quais os jovens lançam mão na disputa por espaço no mercado de trabalho. E, ainda que não desconsiderem o valor das credencias educativas como um critério relevante, os autores salientam que outros elementos devem compor as análises.

Em pesquisas que privilegiam jovens com diferentes graus de escolaridade e faixa-etária, partindo das contribuições de Granovetter, tais autores chegam a conclusões semelhantes a respeito das formas acessadas pelos jovens franceses para a aquisição de um emprego, bem como a qualidade do mesmo.

Esses pesquisadores partem de dois conceitos fundamentais: as redes sociais de ligaçôes fracas e as redes sociais de ligaçôes fortes. Ambos os conceitos dizem respeito às redes de inserção profissional ou redes de busca e de acesso ao primeiro emprego. Estas são definidas "como um conjunto de meios sociais: pessoas, instituições, grupos (...) que os jovens têm a possibilidade de mobilizar para procurar e encontrar um emprego" (Marry, 1983, p. 4).

As redes sociais de ligaçôes fracas são consideradas mais eficazes justamente porque, ao se caracterizarem por ligaçôes mais frouxas, em que circulam grande número de contatos, permitem intenso fluxo de informações que, por sua vez, podem levar a muitas possibilidades de contratos promissores de trabalho. Esse tipo de rede é próprio dos segmentos sociais com maior poder aquisitivo. Já as redes sociais de ligaçôes fortes, comuns nas camadas populares, são consideradas menos eficientes porque se caracterizam por ligaçóes mais estreitas e fechadas, o que reduz as possibilidades de contatos e, consequentemente, não permitem a circulação intensa de informações, não sendo de admirar, portanto, que resultem em empregos precários.

Para os autores franceses citados, esses aspectos podem servir para relativizar as correlaçóes que comumente se estabelecem entre formação e emprego e, assim, contribuir para que os jovens não sejam reduzidos 
Redes de relações sociais e acesso ao emprego entre os jovens...

às suas características escolares. Se o tipo de diploma tem interferência na qualidade do emprego, também é verdade que essa qualidade está sujeita às formas pelas quais o emprego foi conseguido; o que guarda relação direta com o segmento social a que o jovem pertence.

É importante ressaltar que a opção entre uma rede ou outra não diz respeito à esfera das escolhas pessoais. Ou seja, não se trata de vontade ou perspicácia do jovem em saber eleger o melhor para si, ao contrário, pois a configuração das redes pessoais situa-se, a meu ver, na própria dinâmica das relaçôes de classes constituintes da sociedade capitalista. Nesse sentido, é possível dizer que a origem social, mediada pelas redes de busca de acesso aos empregos, determina, em grande medida, as formas de inserção profissional dos jovens com escolarização homogênea.

Convém ressaltar que os segmentos sociais com maior poder aquisitivo tendem a fazer uso de ambas as redes sociais. Isso se explica exatamente porque suas redes de ligaçôes fortes, portanto consideradas "fechadas", não o são verdadeiramente. Assim, à medida que a condição social do candidato ao emprego é mais favorável, entendo ser correto afirmar que as redes de relaçóes sociais que ele utiliza tendem a se fundir em uma única rede e, nesse caso, em redes de ligações fracas. Isso porque, por hipótese, seus empregadores podem ser seus pais, parentes ou vizinhos.

Para os fins deste artigo, selecionei dados referentes às formas utilizadas por egressos do ensino superior, no estado de Santa Catarina, para conseguir seu emprego. Determinado recorte foi feito com base na pesquisa para elaboração da tese de doutorado - defendida em 2004 no Programa de Pós-Graduação em Educação da Universidade Federal de Santa Catarina - sobre egressos de cinco cursos - Administração de Empresas, Direito, História, Pedagogia e Odontologia - de três instituições de ensino: uma federal, uma estadual e uma privada. ${ }^{4}$

No questionário aplicado aos egressos, uma das questões indagava acerca das formas como teriam conseguido o emprego atual. Então, busquei relacionar as formas de acesso ao emprego, declaradas pelos egressos, partindo do salário deles e do salário e escolaridade de seus pais.

As formas mais usuais de acesso ao emprego foram, respectivamente: "intermédio de amigos", "concurso público" e "intermédio da família”, conforme pode ser visto no Gráfico $1 .^{5}$ 


\section{Gráfico 1}

Formas de acesso ao emprego e salário

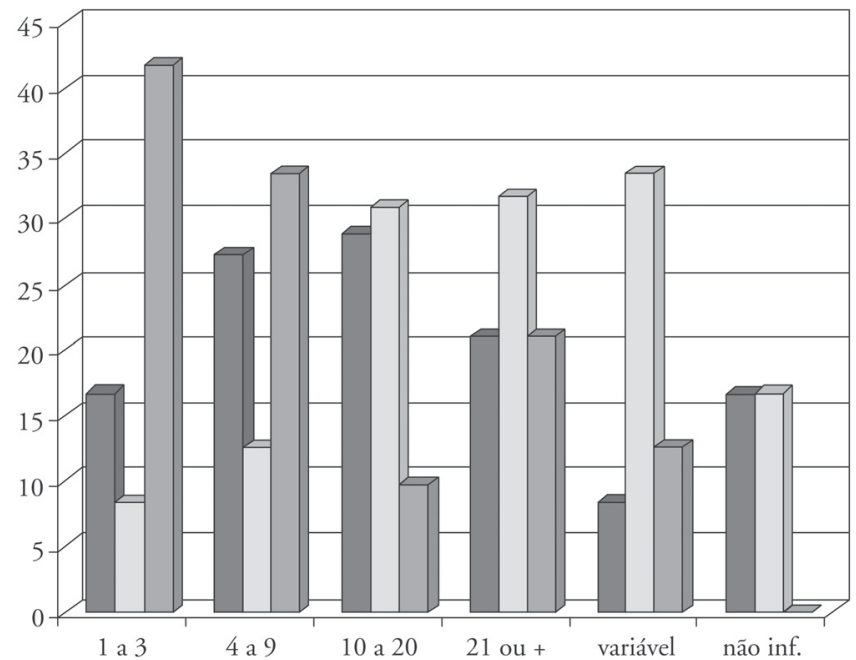

Fonte: Dados obtidos por meio de questionário com egressos de três universidades em Santa Catarina pertencentes aos setores público e privado.

No entanto, é preciso ressaltar que a intensidade com que elas são citadas tende a variar em função do nível salarial no qual o jovem se encontra. Os que declararam ter conseguido emprego por "intermédio de amigos" encontram-se, em maior proporção, na faixa salarial mais alta e, também, entre os que informaram ter uma renda variável. Ou seja, à medida que a escala salarial dos informantes se eleva, aumenta o percentual daqueles que se "beneficiaram" dos amigos para a conquista de seu emprego.

Entre os que mais utilizaram a família para acessar um emprego, estão os egressos com menor faixa salarial. O percentual vai decrescendo conforme se eleva a faixa salarial do egresso. Porém, como demonstrado no gráfico, volta a subir entre os egressos com maiores salários.

Entre os egressos com rendimentos de até três salários mínimos (SM), a influência familiar se revelou como um importante canal de acesso ao emprego, tendo em vista a própria dificuldade do jovem e de sua 
Redes de relações sociais e acesso ao emprego entre os jovens...

família em estabelecer outros contatos fora desse circuito, cuja característica, a julgar pela escolaridade e rendimentos dos pais, também é marcada pela precariedade. A ajuda familiar torna-se a alternativa mais concreta para viabilizar o ingresso desses jovens no mercado de trabalho, e a "qualidade" dessa inserção tende a expressar os limites culturais, sociais e econômicos da família.

O acesso ao emprego atual por meio de concurso público foi uma das vias mais recorrentes entre os egressos. Há certo equilíbrio percentual nessa forma de acesso entre os jovens pertencentes às três faixas salariais: de quatro a nove SM, de 10 a 20, e 21 ou mais SM. Aparece numa proporção bem menor entre os que têm os piores salários, um a três SM; e um pouco mais elevada entre os que recebem 10 a 20 SM. Quanto à origem institucional desses egressos, é expressiva a concentração de jovens provenientes de universidades federais.

A aparência democrática dessa via de acesso ao emprego - já que não é uma forma predominante ou exclusiva de uma faixa salarial - revela seu caráter desigual, quando examinadas as condições salariais dos egressos funcionários públicos e suas ocupações. Ou seja, um professor recém-admitido ganha bem menos do que um juiz de direito ou fiscal da Fazenda; e as possibilidades de ascender na carreira também são bastante contrastantes. ${ }^{6}$ Analisando dessa maneira, a homogeneidade desaparece, uma vez que há egressos no setor público que recebem renda de até três SM, enquanto outros auferem rendimento superior a $20 \mathrm{sM}$.

Assim, acentuo que acessar um emprego por meio de concurso público é uma via "aparentemente" democrática, porque, em princípio, está disponível a todos, sem distinção de origem institucional, sexo e condição social, mas oculta as sutilezas da segmentação social.

Os funcionários públicos situados na faixa salarial mais elevada, que recebem salário igual ou superior a $20 \mathrm{sM}$, constituem um perfil extremamente homogêneo. Todos são do sexo masculino, pertencem ao curso de Direito e são egressos de universidades federais. Analisado em detalhes o perfil desses egressos, é possível perceber que 75\% deles realizaram seus estudos primário e secundário exclusivamente no setor privado, e também seus pais possuem renda elevada e alto nível de escolarização. Apenas em um caso os pais possuíam baixo nível de escolarização e rendimento, embora o filho tenha feito os ensinos primário e médio no setor privado. 
Em primeiro lugar, o que se ressalta é a origem social, pois, se levarmos em consideração dois critérios, renda e escolarização dos pais, a maioria desses egressos do curso de Direito de universidades federais pertence aos segmentos sociais mais favorecidos.

A partir de um estudo com jovens franceses, Audier (1997) informa que os jovens escolarizados e iniciantes na vida ativa representam um importante contingente, que tem no serviço público sua principal via de acesso ao primeiro emprego, especialmente entre as mulheres. Esses jovens possuem, em geral, maior qualificação e ocupam os postos de trabalho mais elevados, quando comparados aos novos contratados do mesmo setor que já tenham iniciado sua vida profissional. Audier (op. cit., p. 14) afirma que "esta preponderância de empregos qualificados, aos quais ascendem os debutantes quando entram na função pública, é ainda mais clara quando comparamos este tipo de posto que eles ocupam na função pública àqueles que lhes oferecem nas empresas".

As exigências colocadas pelos concursos públicos em torno da titulação mínima têm aumentado na França, o que faz com que, cada vez mais, os diplomados ocupem os postos que são disponibilizados. Essa "elitização" torna-se mais acentuada quando se considera o aumento geral de jovens que saem diplomados do sistema escolar e vão disputar o mesmo espaço, quando este tem se tornado atrativo em função da revalorização salarial nos últimos anos, num momento em que se verifica o crescimento do desemprego. Assim, o serviço público tem se constituído num importante canal de ingresso no mercado de trabalho para os jovens escolarizados, mas especialmente entre os portadores de diplomas com nível socioeconômico mais elevado.

Conforme apontado pelos franceses, a fraqueza das ligaçôes fortes parece se confirmar quando cotejamos a escolaridade dos pais com a faixa salarial dos filhos e as formas pelas quais estes declaram ter acessado seu último emprego. Observem o Gráfico 2, na página seguinte. ${ }^{7}$

Não é difícil supor que, para um jovem, cuja escolaridade do pai ou da mãe não ultrapassa os primeiros níveis de ensino, as possibilidades de inserção sob condições mais precárias sejam maiores. Sabemos que a escolaridade baixa está geralmente relacionada às difíceis condiçôes de acesso à escola e à falta de oportunidades para prosseguir nos estudos, características nitidamente associadas à origem social. Contar com a interferência familiar na aquisição do emprego significa fazer uso de redes de ligaçôes fortes igualmente marcadas pela precariedade. 


\section{Gráfico 2}

Escolaridade dos pais e salário do egresso

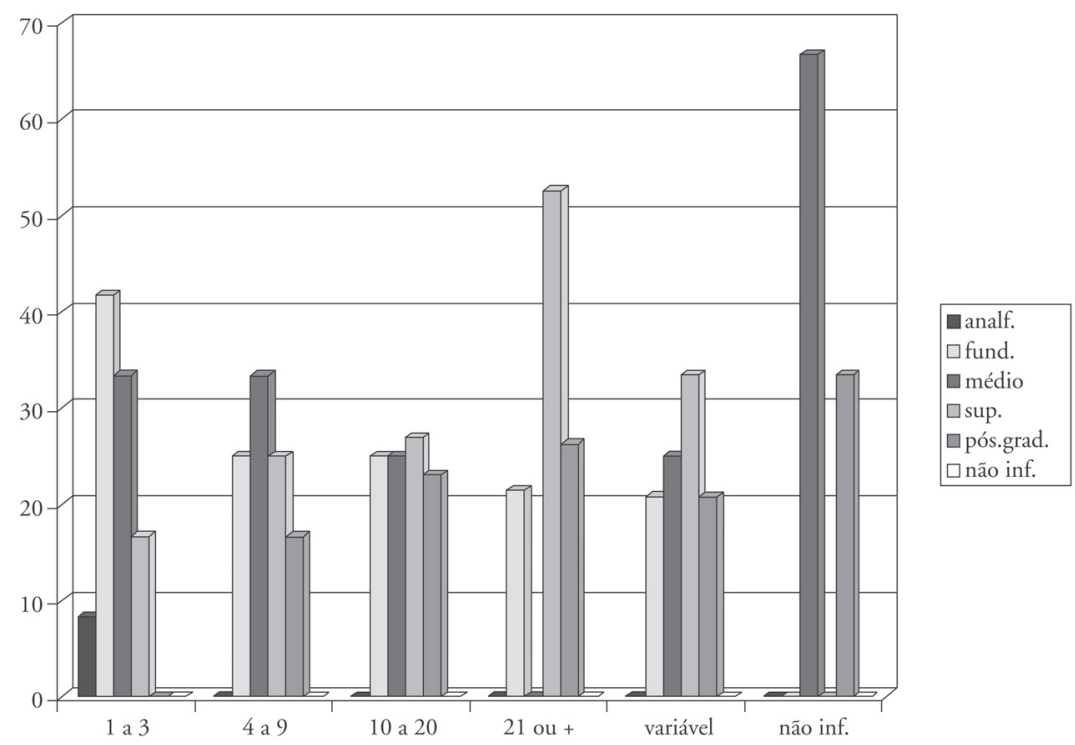

Fonte: Dados obtidos por meio de questionário com egressos de três universidades em Santa Catarina pertencentes aos setores público e privado.

À medida que se avança na análise da faixa salarial dos egressos, é factível perceber que a escolaridade dos pais tende a aumentar. Para os filhos que ganham salários mais altos, a interferência dos amigos é que desponta com relativa expressividade como meio de ascender a um emprego. No entanto, a influência da família volta a crescer mesmo entre os que estão no último patamar salarial. O crescimento da interferência familiar entre os que possuem os mais altos salários pode ser explicado pela possibilidade que os egressos, pertencentes aos meios sociais com maior capital econômico e cultural, têm de utilizar várias formas de acesso ao emprego.

\section{Considerações finais}

Em primeiro lugar, ressalto a expressiva incidência de formas particularistas de acesso ao emprego, independentemente da faixa salarial 
do informante, quando comparadas às demais vias. Excetuando o ingresso no emprego por concurso público (rede formal), o restante das opções (anuncio em jornal, envio de currículo, FAC/estágios, teste seletivo) é parcamente referido. ${ }^{8} \mathrm{O}$ atual modelo de acumulação capitalista - com o desemprego e o enxugamento nos postos de trabalho - requer novos padrôes de concorrência entre os trabalhadores por um espaço no mercado de trabalho. Essa situação talvez contribua para o entendimento das dificuldades pelas vias formais de acesso ao emprego, em contraposição à grande incidência das redes personalizadas.

Nessa perspectiva, recorrer à família ou aos amigos parece ser mais eficiente do que se expor a uma análise de currículo, cujo processo seletivo é altamente competitivo. É importante assinalar que a discussão trata de jovens que ultrapassaram a barreira do vestibular, enfrentaram dificuldades durante o período de graduação, e que estão no momento de disputa por um espaço no mercado de trabalho, o que, aparentemente, os colocaria numa posição de igualdade de condiçóes a partir da obtenção do diploma. O titulo de graduação é apenas um requisito mínimo de nivelamento, uma espécie de senha que autoriza sonhar com possibilidades mais próximas das expectativas criadas.

A inserção profissional dos jovens graduados não se faz com rupturas, mas antes com continuidades e reecaminhamentos, a partir de determinadas estruturas previamente construídas e em constante reconstrução. O diploma de graduação não é o marco zero da vida profissional dos jovens.

As contribuiçõos de estudos desta natureza são de importância fundamental para a apreensão dos processos de inserção profissional dos jovens na atualidade, porque o entendimento de como os diferentes segmentos sociais se mobilizam em torno de seus interesses nos auxilia a desmontar o discurso da empregabilidade. Nessa perspectiva, segundo Gentili (2002, p. 54), ser empregável é dispor de "um conjunto de saberes, competências e credenciais que os habilitem para a competição pelos empregos disponíveis". Nesse tipo de discurso, as "oportunidades" são criadas pelos mais capazes, mais eficientes e competitivos, aqueles que sabem se portar como consumidores de conhecimentos demandados pelo mercado de trabalho.

As reflexões empreendidas neste texto contribuíram para a problematização das questões relativas ao emprego/desemprego e inserção/ 
Redes de relações sociais e acesso ao emprego entre os jovens...

exclusão profissional entre os jovens, colaborando, de um lado, para ultrapassar o mero enfoque economicista - ancorado no discurso das competências - e, de outro, para a aproximação de discussões que recuperem a dinâmica das relações capitalistas como foco principal de análise dos fenômenos sociais.

\section{Recebido em janeiro de 2008 e aprovado em junho de 2008.}

\section{Notas}

1. O autor está considerando como segmento juvenil as pessoas situadas na faixa etária dos 15 aos 24 anos, conforme definição adotada pela Organização das Nações Unidas (ONU). No entanto, adverte que é necessário considerar a especificidade de cada país, pois pode haver variações.

2. Resultados que obtive na pesquisa de doutorado, defendida em 2004 no Programa de PósGraduação em Educação da Universidade Federal de Santa Catarina, revelam que os jovens pesquisados, em sua maioria, trabalham durante o curso de graduação, independente de sua situação econômica (cf. Silva, 2004).

3. Os estudos de Granovetter datam da década de 1970. Porém, neste artigo, faço referência à obra reeditada em francês nos anos de 2000.

4. Para a realização da pesquisa de doutorado foram analisados 176 questionários, aplicados aos egressos do ensino superior que obtiveram seu diploma em 1997 e que tinham até 32 anos de idade em 2001, ano em que ocorreu a coleta de dados. Do total, 161 disseram estar trabalhando.

5. O Gráfico 1 refere-se à seguinte questão formulada, no questionário, aos 161 egressos que afirmaram estar trabalhando em 2001: Como conseguiu seu emprego atual? As opçōes de respostas foram: Anúncio em jornal; Por intermédio de amigos; Por intermédio da faculdade; Por intermédio da família; Internet; Agências de recrutamento; Outros: qual(is)?. Para melhor visualização, optei por representar no Gráfico 1 apenas as três formas mais citadas, motivo pelo qual não aparecem $100 \%$ das respostas.

6. Para uma discussão detalhada desses e outros dados citados ao longo deste artigo, ver Silva (2004).

7. Foi considerado o maior grau de escolaridade apresentado por um dos cônjuges.

8. Por terem sido inexpressivas as opçōes por essas vias, optou-se por não inclui-las no Gráfico 1 .

\section{Referências}

ANTUNES, R. Adeus ao trabalho?: ensaio sobre as metamorfoses e a centralidade do mundo do trabalho. São Paulo: Cortez, 1995.

ANTUNES, R. Os sentidos do trabalho: ensaio sobre a afirmação e a negação do trabalho. 2. ed. São Paulo: Boitempo, 2000. 
AUDIER, F. La fonction publique: un débouché majeur pour les plus diplomés. Économie et Statistique, Paris, n. 304/305, p. 137-148, 1997.

CARDOSO, R.C.L.; SAMPAIO, H. Estudantes universitários e o trabalho. Revista Brasileira de Ciências Sociais, São Paulo, v. 9, n. 26, p. 30-49, 1994.

DEGENNE, A. et al. Les relations sociales au coeur du marché du travail. Sociétés Contemporaines, Paris, n. 5, p. 9-75, mars 1991.

EPIPHANE, D.; MARTINELLI, D. Famille, petites annonces, ANPE... : l'accès à l'emploi des diplomês de l'enseignement supèrieur. Formation Emploi, Paris, n. 58, p. 79-87, avril/juin 1997.

FERRETTI, C. et al. (Org.). Novas tecnologias, trabalho e educação. 2. ed. Petrópolis: Vozes, 1994.

FRIGOTTO, G. Educação e a crise do capitalismo real. 2. ed. São Paulo: Cortez, 1996.

GALLAND, O. Sociologie de la jeunesse. Paris: Armand Colin, 1991.

GENTILI, P. Três teses sobre a relação trabalho e educação em tempos neoliberais. In: LOMBARDI, C. et al. (Org.). Capitalismo, trabalho e educação. São Paulo: Autores Associados, 2002. p. 45-59.

GRANOVETTER, M. Le marché autrement. Paris: Desclée de Brouwer, 2000 .

HARVEY, D. Condição pós-moderna. 4. ed. São Paulo: Loyola, 1994.

MADEIRA, F. Os jovens e as mudanças estruturais na década de 70: questionando pressupostos e sugerindo pistas. Cadernos de Pesquisa, São Paulo, n. 58, p. 15-48, ago. 1986.

MARRY, C. Origine sociale et réseaux d'insertion des jeunes ouvriers. Formation Emploi, Paris, n. 4, p. 3-15, oct./déc. 1983.

POCHMANN, M. A inserção ocupacional e o emprego dos jovens. São Paulo: ABET, 1998. (ABET - Mercado de trabalho, v. 6).

POCHMANN, M. A batalha pelo primeiro emprego. São Paulo: Publisher Brasil, 2000. 
Redes de relações sociais e acesso ao emprego entre os jovens...

SANCHIS, E. Da escola ao desemprego. Rio de Janeiro: Agir, 1997.

SILVA, M.M. Inserção profissional e condição social: trajetórias de jovens graduados no mercado de trabalho. 2004. 249f. Tese (Doutorado) Centro de Ciências da Educação, Universidade Federal de Santa Catarina, Florianópolis.

SILVA, M.M. Formas de acesso ao emprego e origem social: o caso dos egressos do ensino superior. In: Bianchetti, L.; Quartiero, E.M. (Org.). Educação corporativa: mundo do trabalho e do conhecimento: aproximaçōes. Santa Cruz do Sul: EDUnISC; São Paulo: Cortez, 2005. p. 161-181.

TROTTIER, C. Emergência e constituição do campo de pesquisa sobre a inserção profissional. In: Desaulniers, J.B. (Org.). Formação \& trabalho \& Competência. Porto Alegre: EDIPUCRS, 1998. p. 133-178.

TUMOLO, P. Da contestação à conformaçãao: a formação sindical da CUT e a reestruturação capitalista. Campinas: UNICAMP, 2002.

VERNIÈRES, M. (Coord.). L' insertion professionnelle: analyses et débats. Paris: Economica, 1997. 